\title{
Lag effects of size-fractionated particulate matter pollution on outpatient visits for respiratory diseases in Lanzhou, China
}

\author{
Guangyu Zhai ${ }^{1,2, A, D, F \oplus}$, Kuan Zhang ${ }^{1, B-C, F \oplus}$, Guorong Chai ${ }^{2, D-F} \oplus$ \\ 1 School of Economics and Management, Lanzhou University of Technology, Lanzhou 730050, China \\ ${ }^{2}$ School of Management, Lanzhou University, Lanzhou 730000, China \\ A - Research concept and design, B - Collection and/or assembly of data, C - Data analysis and interpretation, \\ $D$ - Writing the article, E - Critical revision of the article, F - Final approval of article
}

Zhai G, Zhang K, Chai G. Lag Effects of Size-Fractionated Particulate Matter Pollution on Outpatient Visits for Respiratory Diseases in Lanzhou, China. Ann Agric Environ Med. 2021; 28(1): 131-141. doi: 10.26444/aaem/132179

\begin{abstract}
Introduction. A large body of evidence suggests that an increase in atmospheric particulate matter (PM) concentrations will lead to an increase in morbidity due to adverse health conditions, such as respiratory diseases (RESD). Lanzhou is located in northwest China, central Gansu Province. Due to limited research and data, the impact of PM on human health have not been systematically acknowledged.

Objective. The aim of the study is to investigate the association between size-fractionated PM pollution and outpatients visits for RESD.

Materials and method. Data on outpatient visits for RESD, air pollutants and meteorological indices in Lanzhou were collected from 1 February 2014 - 31 December 2017, and the associations of three types of PM (PM ${ }_{2.5^{\prime}} \mathrm{PM}_{\mathrm{C}^{\prime}}$ and PM $\left.\mathrm{PM}_{10}\right)$ with outpatient visits for RESD were evaluated using generalized additive models (GAMs).

Results. Findings showed that $\mathrm{PM}_{2.5}$ and $\mathrm{PM}_{\mathrm{C}}$ had the most significant impact on outpatient visits for RESD at seven cumulative lag days. $\mathrm{PM}_{10}$ was not significantly associated with outpatient visits for RESD. In subgroup analysis, the impact of atmospheric PM on outpatient visits for RESD was significantly modified by gender and age; men, and children aged 0-5 years old, were more sensitive to $\mathrm{PM}_{2.5}$ pollution.

Conclusions. Increased atmospheric PM concentration is associated with an increase in outpatient visits for RESD, and it has a lag effect. The increase in outpatient visits for RESD appears to be driven by increased PM $_{2.5}$ concentrations. The results obtained may provide reference values for formulating preventive strategies to protect the population from the adverse impact of PM pollution.
\end{abstract}

\section{Key words}

Particulate matter; Respiratory diseases; Daily outpatient visits; Generalized additive model

\section{Abbreviations}

GAM - Generalized Additive Model; RESD - Respiratory Diseases; AIC - Akaike's Information Criterion; ER - Excessive Risk; PM - Particulate Matter

\section{INTRODUCTION}

With the acceleration of industrialization and urbanization in recent years, energy consumption has dramatically increased with a subsequent increase in air pollution, which poses the most severe environmental health risk globally [1]. According to the China Ecological Environment Status Bulletin 2016, air quality index (AQI) greater than 100 was considered to exceed the standard; 254 out of 338 (75.1\%) cities at or above the prefectural level in China did not meet the minimum standards for environmental air quality in 2016; the number of days with heavy pollution and above were dominated by particulate matter $2.5\left(\mathrm{PM}_{2.5}\right)$, and $\mathrm{PM}_{10}$ accounted for $80.3 \%$ and $20.4 \%$, respectively, of the total. Atmospheric PM pollution is currently the leading cause of smog in China. Atmospheric PM includes total suspended particulates (TSP), inhalable particulates, fine particulates and ultrafine particulates. Among them, inhalable particulates (also

Address for correspondence: Kuan Zhang, Lanzhou University of Technology, Lanzhou, China

E-mail: 2039146824@qq.com

Received: 02.11.2020; accepted: 04.01.2021; first published: 21.01.2021 known as $\mathrm{PM}_{10}$ ) are defined as particulates that can enter the respiratory tract and have an aerodynamic diameter of $\leq 10 \mu \mathrm{m}$. Fine particulates, also known as $\mathrm{PM}_{2,5}$, are small particles easily retained in the terminal bronchioles and alveoli, with an aerodynamic diameter of $\leq 2.5 \mu \mathrm{m}$; some finer ones can enter the bloodstream through the alveoli [2-3]. $\mathrm{PM}_{\mathrm{C}}$ is a PM with an aerodynamic diameter of 2.5-10 $\mu \mathrm{m}$ [4].

Over the last few years, there has been intense research interest in the adverse effects of environmental pollution on human health. Previous studies have demonstrated that short-term exposure to atmospheric PM is associated with increased morbidity, hospitalization and mortality due to respiratory diseases (RESD) [5-9]. Epidemiological studies conducted in China and elsewhere have mostly focused on all-cause mortality outcomes. However, unlike Western countries, outpatient visits far exceed hospital admissions in China, indicating an acute effect of PM pollution on population health [7]. Therefore, it appears that morbidity may be a more appropriate index for quantifying impact of PM pollution on health rather than mortality. Existing studies on the impact of atmospheric PM with different particle sizes on RESD in China have so far been conducted 
in Beijing, Nanjing, Dongguan, Guangzhou and Ningbo [4;7;10-12]. However, the components of atmospheric PM vary significantly from region to region, and its impact on health is also different [7]. In previous studies, outpatient data were rarely used to simultaneously evaluate the impact of three types of $\mathrm{PM}\left(\mathrm{PM}_{25}, \mathrm{PM}_{\mathrm{C}}\right.$, and $\left.\mathrm{PM}_{10}\right)$ on patients with RESD, with stratification by gender and age groups.

Lanzhou, the capital and largest city of central Gansu Province in northwest China, is an industrial city dominated by petrochemicals, metallurgy and machinery. It is surrounded by mountains, forming a bead-like river valley terrain with canyons and basins, and to the northeast of Lanzhou lies the Qinghai-Tibet Plateau. Due to its topographic conditions and geographic location, the atmosphere of Lanzhou remains in an ultra-stable state, which is not conducive to the diffusion and dilution of atmospheric pollutants. Furthermore, fossil fuel consumption has increased due to the acceleration of industrialization and urbanization and increased ownership of motor vehicles, thus raising the atmospheric $\mathrm{PM}_{25}$ concentration. Also, the Tengger Desert, one of the three major dust sources in China, is only 200 kilometers from Lanzhou, and the Badain Jaran Desert is located 500 kilometers to the northwest of Lanzhou; natural dust fall is therefore severe and sand-dust weather frequently occurs in Lanzhou [13]. Studies have shown that surface soil accounts for $46.33 \%$ of $\mathrm{PM}_{10}$ in Lanzhou due to the dry weather [14], so atmospheric $\mathrm{PM}_{10}$ concentration in Lanzhou is increased by sand-dust weather. Between 2007-2017, the annual average $\mathrm{PM}_{10}$ concentration in Lanzhou exceeded the second-level standard of environmental air quality in China $\left(70 \mu \mathrm{g} / \mathrm{m}^{3}\right)$. The $\mathrm{PM}_{2.5}$ concentration remained at $60-70 \mu \mathrm{g} / \mathrm{m}^{3}$, which also exceeded the national second-level standard by 1.5 times. Given the increasing air pollution and concerns with adverse health effects, there has been an increasing number of research studies on atmospheric particulate pollutants in Lanzhou, focusing on TSP, dust fall and floating dust. There are limited studies on pollution characteristics, chemical composition and sources of $\mathrm{PM}_{10}$ and $\mathrm{PM}_{2.5}$ [15-16]. To our knowledge, no study has yet evaluated the impact of $\mathrm{PM}_{2.5}$, $\mathrm{PM}_{\mathrm{C}}$ and $\mathrm{PM}_{10}$ on RESD in Lanzhou.

\section{OBJECTIVES}

The aim of the study was to investigate the association between size-fractionated PM pollution and outpatients visits for RESD, with the objective of clarifying the adverse effects of RESD due to PM pollution in Lanzhou, which may help in formulating preventive strategies.

\section{MATERIALS AND METHOD}

Study area. Lanzhou is the capital of Gansu Province, located in northwestern China and central Gansu Province $\left(102^{\circ} 24^{\prime}-104^{\circ} 33^{\prime} \mathrm{E}, 35^{\circ} 23^{\prime}-37^{\circ} 42^{\prime} \mathrm{N}\right)$. It has a typical temperate semi-arid continental monsoon climate. The annual average temperature is $10.3^{\circ} \mathrm{C}$, the summer is warm and short and the winter is cold and long. During the summer, precipitation is small and concentrated; it is dry and windy and the day-night temperature difference is substantial. The city covers a total area of 13,100 square kilometers and the total population of the municipal district is about three million.
Data sources. Data on daily outpatient visits for RESD in Lanzhou from 1 February 2014 - 31 December 2017 were obtained from three local Grade A Class 3 hospitals. These included the home address, gender, age, date of outpatient visit, disease diagnosis and visit ID of patients. Non-local patients were excluded based on their home addresses. Disease diagnoses were coded according to the $10^{\text {th }}$ edition of the International Classification of Diseases (ICD-10) codes (J00-J99). The disease of concern primarily included upper respiratory tract infection (URTI; ICD-10: J00-J06 and J30-J39), lower respiratory tract infection (LRTI; ICD-10: J20-J22 and J40-J47), and asthma (ICD-10: J45-J46). Asthma accounted for $3.24 \%$ of all outcomes, upper respiratory tract infections for $69.51 \%$, lower respiratory tract infections for $20.59 \%$ and others for $6.67 \%$.

Data on atmospheric pollutants were obtained from the national urban air quality real-time publishing platform (http://106.37.208.233:20035/), and daily monitoring data of Lanzhou were selected, including $\mathrm{PM}_{25}, \mathrm{PM}_{10}$, sulfur dioxide $\left(\mathrm{SO}_{2}\right)$, and nitrogen dioxide $\left(\mathrm{NO}_{2}\right)$. The daily average concentration of pollutants was the arithmetic mean of the data from the four State-controlled monitoring points in Lanzhou. Both data integrity and consistency complied with the requirements of the national ambient air quality monitoring specifications, without abnormally high or low values and missing values, but with higher accuracy. The location distribution of hospitals and environmental monitoring points in Lanzhou are shown in Figure 1. The meteorological data came from Gansu Meteorological Bureau, which included average temperature and relative humidity.

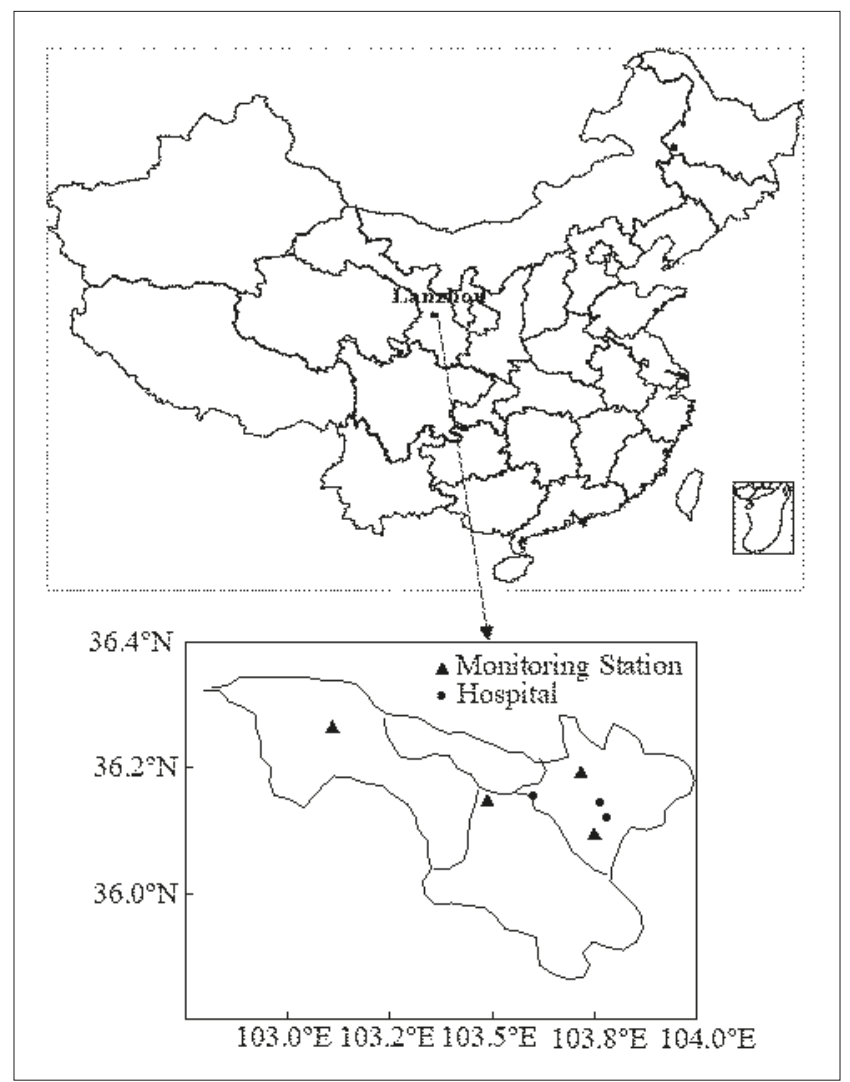

Figure 1. Location of Lanzhou in China and air pollution monitor and hospital 
Statistical analysis. Since the proportion of daily outpatient visits for RESD in the total population was small and approximately conforms to the Poisson distribution, the short-term impact of atmospheric PM on daily outpatient visits for RESD was analyzed using a semi-parametric generalized additive model (SGAM) based on Poisson regression. The basic model formula is as follows:

$$
\begin{gathered}
\log \left[E\left(Y_{\mathrm{t}}\right)\right]=\alpha+\beta Z_{\mathrm{t}}+n s(\text { time }, d f)+n s\left(\text { Temp }_{\mathrm{t}}, d f\right)+ \\
+n s\left(R H_{\mathrm{t}}, d f\right)+\text { DOW }+ \text { Holiday }
\end{gathered}
$$

In the formula, $Y_{t}$ represents the outpatient visits on the $t$ day; $E\left(Y_{t}\right)$ represents the expected outpatient visits on the $t$ day; $\alpha$ is the intercept; $Z_{t}$ indicates the pollutant concentration on the $t$ day; $\beta$ is the regression coefficient; $n s$ indicates the natural cubic spline; time is the time variable; Temp indicates the average temperature on the $t$ day; $R H_{t}$ represents the average relative humidity on the $t$ day; $D O W$ indicates the day-of-the-week effect; Holiday indicates the holiday effect; both DOW and Holiday were used as dummy variables.

The degree of freedom of each variable in the model was determined according to the Akaike Information Criterion (AIC). More specifically, seven was selected as the degree of freedom of time variable to eliminate secular trends and seasonality. To control for the interference of confounding factors in the model [17], the natural cubic spline with a degree of freedom of three was selected, thus controlling the influence of temperature and humidity [18-19]. The PM pollution effect was quantitatively evaluated through the increase in the value of the relative risk of outpatient visits for every $10 \mu \mathrm{g} / \mathrm{m}^{3}$ increase in pollutant concentration [18;20-21]. The results were expressed as excess risk $(E R)$, which was estimated using: $E R=\left(e^{10 \times \beta}-1\right) \times 100 \%$.

Previously, it has been confirmed that the impact of air pollutants on the respiratory system has a lag effect, and the lag effect alone may reduce the association between air pollutants and disease [7;22]. Therefore, single lag effects (lag $1, \operatorname{lag} 2, \operatorname{lag} 3, \operatorname{lag} 4, \operatorname{lag} 5, \operatorname{lag} 6$, and $\operatorname{lag} 7 \mathrm{~d})$ and cumulative lag effects (lag01, lag02, lag03, lag04, lag05, lag06, and lag07d) of $\mathrm{PM}_{2.5}, \mathrm{PM}_{\mathrm{C}}$, and $\mathrm{PM}_{10}$ on outpatient visits for RESD were analyzed in this study. For the single lag effect, lag $\mathrm{x}(\mathrm{x}=1,2$, $3, \ldots, 7)$ represents lag associated with the mass concentration of PM in the previous $x$ days; for the cumulative lag effect, lag $0 x(x=1,2,3, \ldots, 7)$ represents lag associated with the average mass concentration of PM on the current day and the previous $\mathrm{x}$ days.

The outpatient medical records were stratified based on gender (male, female), age (0-5, 6-14, 15-59, $\geq 60$-yearsold), and season. The impact of $\mathrm{PM}_{2.5}, \mathrm{PM}_{\mathrm{C}}$, and $\mathrm{PM}_{10}$ on daily outpatient visits in these different subgroups and their seasonal differences were then explored.

As shown in Table S1, the two-pollutant and multi-

\begin{tabular}{|c|c|c|c|c|c|c|c|}
\hline Model* & Total & Male & Female & $0-5$ years & $6-14$ years & $15-59$ years & $\geq 60$ years \\
\hline \multicolumn{8}{|l|}{$\mathrm{PM}_{2.5}$} \\
\hline \multicolumn{8}{|c|}{ df for temporal trends } \\
\hline $\mathrm{df}=5 /$ year & $1.441(0.977,1.906)$ & $1.401(0.926,1.878)$ & $1.487(1.012,1.965)$ & $2.571(1.973,3.171)$ & $0.664(-.111,1.446)$ & $-0.021(-.535,0.497)$ & $0.793(0.170,1.420)$ \\
\hline $\mathrm{df}=6 /$ year & $1.322(0.867,1.779)$ & $1.278(0.812,1.746)$ & $1.373(0.905,1.842)$ & $2.38(1.797,2.966)$ & $0.532(-.242,1.312)$ & $-0.056(-.571,0.462)$ & $0.706(0.088,1.329)$ \\
\hline $\mathrm{df}=8 /$ year & $1.434(0.802,1.869)$ & $1.109(0.261,1.460)$ & $1.463(0.322,1.907)$ & $2.243(1.734,2.754)$ & $0.562(-.327,0.958)$ & $-0.029(-.555,0.501)$ & $0.728(0.095,1.365)$ \\
\hline $\mathrm{df}=4$ & $1.351(0.888,1.816)$ & $1.317(0.843,1.794)$ & $1.391(0.917,1.867)$ & $2.464(1.868,3.064)$ & $0.507(-0.27,1.29)$ & $-0.077(-.592,0.442)$ & $0.766(0.140,1.395)$ \\
\hline $\mathrm{df}=5$ & $1.325(0.861,1.792)$ & $1.298(0.822,1.776)$ & $1.358(0.882,1.835)$ & $2.427(1.829,3.028)$ & $0.557(-.222,1.341)$ & $-0.097(-.615,0.424)$ & $0.687(0.060,1.318)$ \\
\hline$d f=6$ & $1.290(0.826,1.756)$ & $1.261(0.785,1.740)$ & $1.324(0.848,1.802)$ & $2.387(1.789,2.989)$ & $0.497(-.284,1.284)$ & $-0.121(-0.64,0.400)$ & $0.648(0.022,1.279)$ \\
\hline \multicolumn{8}{|l|}{$\mathrm{PM}_{\mathrm{c}}$} \\
\hline \multicolumn{8}{|c|}{ df for temporal trends } \\
\hline $\mathrm{df}=6 /$ year & $0.425(0.195,0.655)$ & $0.405(0.169,0.642)$ & $0.447(0.213,0.683)$ & $0.701(0.402,1.023)$ & $0.328(-0.071,0.728)$ & $0.032(-0.221,0.287)$ & $0.189(-0.109,0.488)$ \\
\hline $\mathrm{df}=8 /$ year & $0.421(-0.098,0.641)$ & $0.412(-0.116,0.641)$ & $0.432(-0.191,0.735)$ & $0.676(0.338,1.092)$ & $0.329(-0.079,0.74)$ & $0.034(-0.224,0.292)$ & $0.190(-0.134,0.474)$ \\
\hline \multicolumn{8}{|c|}{ df for temperature } \\
\hline $\mathrm{df}=4$ & $0.472(0.242,0.704)$ & $0.453(0.216,0.691)$ & $0.495(0.260,0.731)$ & $0.761(0.459,1.063)$ & $0.379(-0.016,0.775)$ & $0.057(-0.195,0.31)$ & $0.229(-0.071,0.529)$ \\
\hline$d f=5$ & $0.474(0.244,0.705)$ & $0.456(0.219,0.694)$ & $0.494(0.260,0.730)$ & $0.756(0.461,1.069)$ & $0.4(0.006,0.796)$ & $0.056(-0.197,0.309)$ & $0.210(-0.089,0.51)$ \\
\hline $\mathrm{df}=6$ & $0.493(0.263,0.724)$ & $0.478(0.241,0.715)$ & $0.511(0.277,0.747)$ & $0.791(0.491,1.092)$ & $0.431(0.036,0.828)$ & $0.057(-0.196,0.311)$ & $0.235(-0.063,0.535)$ \\
\hline \multicolumn{8}{|l|}{$\mathrm{PM}_{10}$} \\
\hline \multicolumn{8}{|c|}{ df for temporal trends } \\
\hline $\mathrm{df}=5 /$ year & $0.478(0.302,0.654)$ & $0.462(0.281,0.643)$ & $0.496(0.317,0.676)$ & $0.816(0.589,1.045)$ & $0.310(0.007,0.615)$ & $0.024(-0.169,0.218)$ & $0.238(0.01,0.467)$ \\
\hline $\mathrm{df}=6 /$ year & $0.438(0.265,0.611)$ & $0.421(0.243,0.599)$ & $0.458(0.281,0.635)$ & $0.757(0.534,0.98)$ & $0.265(-0.038,0.570)$ & $0.021(-0.183,0.205)$ & $0.207(-0.02,0.435)$ \\
\hline $\mathrm{df}=8 /$ year & $0.429(0.012,0.647)$ & $0.470(0.0204,0.604)$ & $0.490(0.201,0.660)$ & $0.764(0.534,0.965)$ & $0.294(-0.019,0.509)$ & $0.019(-0.182,0.215)$ & $0.200(-0.033,0.434)$ \\
\hline \multicolumn{8}{|c|}{ df for temperature } \\
\hline $\mathrm{df}=5$ & $0.465(0.29,0.639)$ & $0.451(0.271,0.631)$ & $0.481(0.303,0.659)$ & $0.794(0.568,1.019)$ & $0.311(0.01,0.613)$ & $0.02(-0.174,0.213)$ & $0.216(-0.013,0.445)$ \\
\hline$d f=6$ & $0.470(0.296,0.644)$ & $0.457(0.278,0.637)$ & $0.485(0.307,0.663)$ & $0.804(0.579,1.029)$ & $0.319(0.017,0.622)$ & $0.017(-0.176,0.211)$ & $0.225(-0.003,0.454)$ \\
\hline
\end{tabular}

Table S1. Percentage increase in RESD daily outpatients for a $10 \mathrm{ug} / \mathrm{m}^{3}$ increase in daily PM pollutants on lag 07 day in sensitivity analyses 
pollutant models were established by introducing other coexisting pollutants, and the degree of freedom of the time variable $(\mathrm{df}=6-10)$ was altered for sensitivity analysis. All statistical analyses were conducted using R software (version 3.4.4) with 'mgcv' package and $P<0.05$ was considered to be statistically significant.

\section{RESULTS}

Descriptive data on daily outpatient visits for RESD, the daily average concentration of air pollutants and meteorological data, are shown in Table 1. A total of 633 people had an outpatient visit for RESD, on average, every day in the three hospitals in Lanzhou from 1 February 2014 - 31 December 2017. These included 342 males and 291 females (1.18:1) and 300 were aged $0-5$ years, 93 aged $6-14$ years, 188 aged $15-59$ years and 52 aged $\geq 60$ years. The daily average concentration of $\mathrm{PM}_{2.5}, \mathrm{PM}_{\mathrm{C}}, \mathrm{PM}_{10}, \mathrm{NO}_{2}$ and $\mathrm{SO}_{2}$ was $52.81 \mu \mathrm{g} / \mathrm{m}^{3}$, $69.91 \mu \mathrm{g} / \mathrm{m}^{3}, 122.65 \mu \mathrm{g} / \mathrm{m}^{3}, 45.88 \mu \mathrm{g} / \mathrm{m}^{3}$ and $21.91 \mu \mathrm{g} / \mathrm{m}^{3}$, respectively. According to the annual concentration limits specified in Ambient Air Quality Standard (GB3095-2012), the second-level annual average concentration threshold of $\mathrm{PM}_{2.5}, \mathrm{PM}_{10}$ and $\mathrm{NO}_{2}$ were $35 \mu \mathrm{g} / \mathrm{m}^{3}, 70 \mu \mathrm{g} / \mathrm{m}^{3}$ and $40 \mu \mathrm{g} / \mathrm{m}^{3}$, respectively; the concentration of $\mathrm{PM}_{2.5}, \mathrm{PM}_{10}$, and $\mathrm{NO}_{2}$, exceeded the national second-level standard. In contrast, the annual average concentration of $\mathrm{SO}_{2}$ did not exceed the national second-level standard $\left(60 \mu \mathrm{g} / \mathrm{m}^{3}\right)$ during the study period. The annual average temperature and annual average relative humidity were $11.66^{\circ} \mathrm{C}$ and $50.94 \%$, respectively.

As shown in Figure 2, the concentrations of $\mathrm{PM}_{2.5}, \mathrm{PM}_{\mathrm{C}}$ and $\mathrm{PM}_{10}$ in Lanzhou in 2014-2017 displayed an evident seasonal trend, with a decline in summer and an increase in winter.

Table 1. Descriptive statistics on RESD outpatient visits, air pollutant levels and meteorological variables in Lanzhou during 2014-2017

\begin{tabular}{|c|c|c|c|c|c|c|}
\hline \multirow{2}{*}{ Variable } & \multirow{2}{*}{$\bar{x} \pm \mathrm{SD}$} & \multirow{2}{*}{ Min } & \multicolumn{3}{|c|}{ Percentile } & \multirow{2}{*}{ Max } \\
\hline & & & $P_{25}$ & $P_{50}$ & $P_{75}$ & \\
\hline \multicolumn{7}{|c|}{ RESD outpatient visits } \\
\hline Total & $633.00 \pm 243.82$ & 1.00 & 476.00 & 598.50 & 736.00 & 2130.00 \\
\hline Male & $342.43 \pm 128.84$ & 1.00 & 259.00 & 323.00 & 396.00 & 1103.00 \\
\hline Female & $290.56 \pm 116.80$ & 1.00 & 216.00 & 276.00 & 339.00 & 1027.00 \\
\hline $0-5$ years & $299.92 \pm 121.19$ & 1.00 & 224.00 & 276.50 & 342.00 & 1041.00 \\
\hline $6-14$ years & $93.37 \pm 49.89$ & 1.00 & 63.00 & 81.00 & 107.00 & 422.00 \\
\hline $15-59$ years & $188.09 \pm 88.93$ & 1.00 & 118.00 & 187.00 & 238.00 & 556.00 \\
\hline$\geq 60$ years & $51.62 \pm 30.90$ & 1.00 & 25.00 & 51.00 & 69.00 & 189.00 \\
\hline \multicolumn{7}{|c|}{ Meteorological factors } \\
\hline $\begin{array}{l}\text { Mean } \\
\text { temperature }\left({ }^{\circ} \mathrm{C}\right)\end{array}$ & $11.66 \pm 9.68$ & -12.30 & 3.40 & 13.07 & 19.90 & 30.40 \\
\hline $\begin{array}{l}\text { Relative humidity } \\
\text { (\%) }\end{array}$ & $50.94 \pm 15.14$ & 18.00 & 39.43 & 50.66 & 62.00 & 96.09 \\
\hline \multicolumn{7}{|l|}{ Air pollutants } \\
\hline $\mathrm{PM}_{2.5}\left(\mu \mathrm{g} / \mathrm{m}^{3}\right)$ & $52.81 \pm 26.94$ & 12.73 & 35.24 & 45.14 & 62.40 & 269.43 \\
\hline $\mathrm{PM}_{c}\left(\mu \mathrm{g} / \mathrm{m}^{3}\right)$ & $69.91 \pm 61.91$ & 2.27 & 41.31 & 58.68 & 84.21 & 1251.40 \\
\hline $\mathrm{PM}_{10}\left(\mu \mathrm{g} / \mathrm{m}^{3}\right)$ & $122.65 \pm 78.83$ & 18.98 & 80.50 & 107.63 & 144.76 & 1484.54 \\
\hline $\mathrm{SO}_{2}\left(\mu \mathrm{g} / \mathrm{m}^{3}\right)$ & $21.91 \pm 14.18$ & 3.54 & 10.82 & 17.94 & 29.68 & 81.87 \\
\hline $\mathrm{NO}_{2}\left(\mu \mathrm{g} / \mathrm{m}^{3}\right)$ & $45.88 \pm 15.85$ & 7.80 & 36.36 & 45.30 & 52.76 & 146.60 \\
\hline
\end{tabular}

Note: $\bar{x}, \mathrm{SD}, \mathrm{Min}, \mathrm{Max}, \mathrm{P}_{25^{\prime}} \mathrm{P}_{75}$ represented the mean, standard deviation, minimum, maximum the 25 th percentile, and the 75 th percentile of variables, respectively.
Table 2. Spearman correlation coefficients between daily air pollutants and weather conditions in Lanzhou, 2014-2017

\begin{tabular}{lllllll}
\hline Pollutants & $\mathrm{PM}_{2.5}$ & $\mathrm{PM}_{\mathrm{c}}$ & $\mathrm{PM}_{10}$ & $\mathrm{SO}_{2}$ & $\mathrm{NO}_{2}$ & Temperature \\
\hline $\mathrm{PM}_{\mathrm{c}}$ & $0.51^{*}$ & & & & & \\
\hline $\mathrm{PM}_{10}$ & $0.81^{*}$ & $0.72^{*}$ & & & & \\
\hline $\mathrm{SO}_{2}$ & $0.64^{*}$ & $0.37^{*}$ & $0.56^{*}$ & & & \\
\hline $\mathrm{NO}_{2}$ & $0.41^{*}$ & $0.35^{*}$ & $0.42^{*}$ & $0.38^{*}$ & & \\
\hline Temperature & $-0.46^{*}$ & $-0.14^{*}$ & $-0.33^{*}$ & $-0.62^{*}$ & $-0.20^{*}$ & \\
\hline Humidity & $-0.14^{*}$ & $-0.47^{*}$ & $-0.34^{*}$ & $-0.19^{*}$ & $-014^{*}$ & $-0.08^{*}$ \\
\hline${ }^{*}<<0.01$ & & & & & &
\end{tabular}

The change in the trend of outpatient visits for RESD was consistent for $\mathrm{PM}_{2.5}$; outpatient visits were lower in summer and peaked in the winter.

The estimated Spearman correlation coefficients between air pollutants and meteorological factors are listed in Table 2. There were significant positive correlations among $\mathrm{PM}_{25}, \mathrm{PM}_{C}$, $\mathrm{PM}_{10}, \mathrm{NO}_{2}$ and $\mathrm{SO}_{2}(p<0.05) . \mathrm{PM}_{25}, \mathrm{PM}_{\mathrm{C}}, \mathrm{PM}_{10}, \mathrm{NO}_{2}$ and $\mathrm{SO}_{2}$ were negatively correlated with daily average temperature and average relative humidity $(p<0.05)$. Atmospheric pollutants had strong correlations with meteorological factors.

After accounting for confounding factors, GAM analysis was conducted to assess the impact of the daily average concentration of $\mathrm{PM}_{2.5}, \mathrm{PM}_{\mathrm{C}}$ and $\mathrm{PM}_{10}$ on daily outpatient visits for RESD in subgroups on the same day and different lag days. It was observed that: the single lag effect of $\mathrm{PM}_{2.5}$ on the entire population was not statistically significant at lag5, and statistically significant on other lag days (lag0-lag4, lag6-7). The cumulative lag effect of $\mathrm{PM}_{2.5}$ was statistically significant throughout the cumulative lag period (lag01-lag07).

The single lag effect of $\mathrm{PM}_{\mathrm{C}}$ on the entire population was only statistically significant at lag7, and its cumulative lag effect was not statistically significant throughout the cumulative lag period (lag01-lag07).

Moreover, the single lag effect of $\mathrm{PM}_{10}$ on the entire population was not statistically significant throughout the lag period (lag0-lag7), with no evidence of statistical significance detected in its cumulative lag effect throughout the cumulative lag phase (lag01-lag07).

Subgroup analyses were conducted according to age and gender. The impact of $\mathrm{PM}_{2.5}, \mathrm{PM}_{\mathrm{C}}$ and $\mathrm{PM}_{10}$ on outpatient visits in each subgroup are shown in Tables 3-5. In the analysis by gender, the single lag effect of $\mathrm{PM}_{2.5}$ on men was not statistically significant at lag5, and its harmful effect was most remarkable at lag7, in which case outpatient visits increased by 0.793 (95\% CI: $0.349,1.239)$ for every $10 \mu \mathrm{g} / \mathrm{m}^{3}$ increase in $\mathrm{PM}_{2.5}$ concentrations. Its single lag effect on women was not statistically significant at 4 and 5 lag days (lag4-lag5), and the maximum ER (0.832) was found at lag7 (95\% CI: 0.395, 1.272). The cumulative lag effect of $\mathrm{PM}_{2.5}$ on men and women were both statistically significant throughout the cumulative lag phase, and outpatient visits of men were higher than those of women for every $10 \mu \mathrm{g} / \mathrm{m}^{3}$ increase in $\mathrm{PM}_{2.5}$ concentration.

Furthermore, the single lag effect of $\mathrm{PM}_{\mathrm{C}}$ between men and women was statistically significant only at lag7, and its cumulative lag effects on men and women were not statistically significant throughout the cumulative lag phase. The single and cumulative lag effects of $\mathrm{PM}_{10}$ on men and women were not statistically significant throughout the lag phase. 

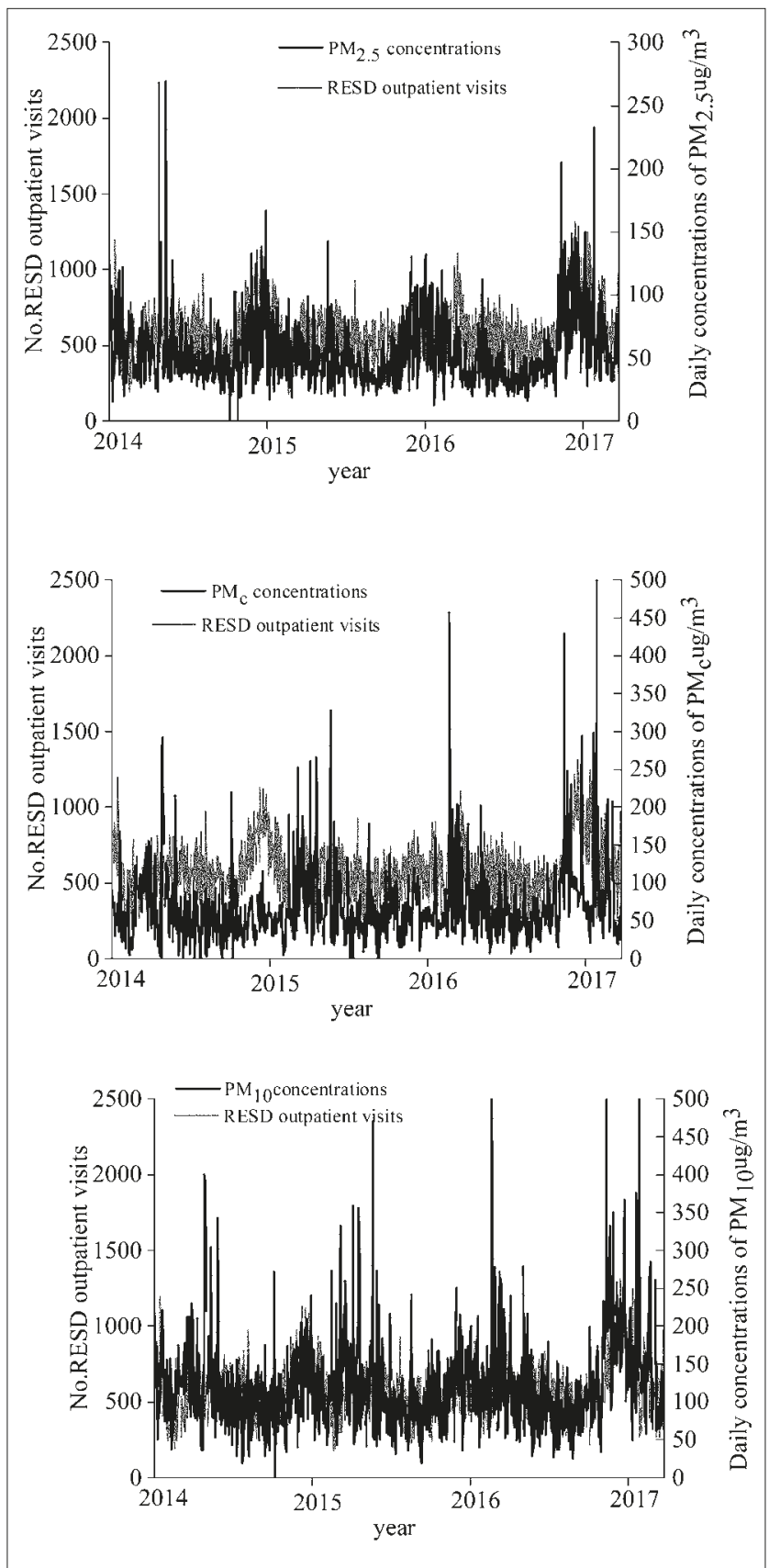

Figure 2. Concentrations of $\mathrm{PM}_{25^{\prime}} \mathrm{PM}_{\mathrm{c}}$ and $\mathrm{PM}_{10}$ from 2014 to 2017 in Lanzhou in different season

In the subgroup analysis by age, the single and cumulative lag effects of $\mathrm{PM}_{2.5}$ on children aged $0-5$ years were statistically significant throughout the lag phase, with no statistical significance in people aged 6-14 and 15-59. Among people aged $\geq 60$ years, the single lag effect was statistically significant at 1-3 lag days (lag1-lag3), whereas the cumulative lag effect was statistically significant at 2-4 cumulative lag days (lag02-lag04) and seven cumulative lag days (lag07). Overall, the risk of outpatient visits by children aged $0-5$ years was higher than that of other age subgroups for every $10 \mu \mathrm{g} / \mathrm{m}^{3}$ increase in $\mathrm{PM}_{2.5}$ concentration.

Furthermore, the single lag effect of $\mathrm{PM}_{\mathrm{C}}$ on children aged $0-5$ years was statistically significant at 6-7 lag days (lag6-lag7). In contrast, this effect on people aged 6-14,
$15-59$ and $\geq 60$-years-old was not statistically significant. The cumulative lag effect of $\mathrm{PM}_{\mathrm{C}}$ was not statistically significant in all age subgroups.

Also, the single lag effect of $\mathrm{PM}_{10}$ in each age subgroup was not statistically significant; its cumulative lag effect on children aged $0-5$ years was statistically significant only at seven cumulative lag days (lag07), with no evidence of statistical significance observed throughout the cumulative lag phase in other age subgroups.

Based on the findings of lag effects of the single-pollutant model, population-wide daily outpatient visits for RESD at seven cumulative lag days (lag07) with the most significant impact were selected to fit the multi-pollutant model. As Table 6 shows, after controlling for gaseous pollutants $\mathrm{SO}_{2}$ and $\mathrm{NO}_{2}$ separately or simultaneously in the multi-pollutant model, ER of $\mathrm{PM}_{2.5}, \mathrm{PM}_{\mathrm{C}}$ and $\mathrm{PM}_{10}$ on outpatient visits for RESD had smaller changes than that in the single-pollutant model, and the direction remained unchanged, indicating that the fit of the single-pollutant model was better and the results were relatively stable.

The exposure-response curves between concentrations of $\mathrm{PM}_{2.5}, \mathrm{PM}_{\mathrm{C}}$ and $\mathrm{PM}_{10}$ and outpatient visits of children for RESD at seven cumulative lag days (lag07) are shown in Figure 3. The exposure-response relationship of each of the three types of PM was non-linear under different pollution concentrations when other pollutants were not adjusted for. When the $\mathrm{PM}_{2.5}$ concentration was $10-55 \mu \mathrm{g} / \mathrm{m}^{3}$, the curve was relatively steep, whiles the curve flattened out beyond this concentration. The exposure-response curves of $\mathrm{PM}_{C}$ and $\mathrm{PM}_{10}$ were an inverted $\mathrm{U}$-shaped, and the relative risk initially increased and then declined with an increase in the concentration of each PM.

\section{DISCUSSION}

In the current study, SGAM was used to evaluate the association of size-fractionated PM pollution with outpatient visits for RESD involving 905,188 cases in Lanzhou, China. Findings showed significant associations of increased $\mathrm{PM}_{2.5}$ concentrations with increased daily outpatients visits for RESD, with modest associations for larger particles.

Previous studies showing that increased $\mathrm{PM}_{2.5}$ concentrations could significantly increase outpatient visits for RESD $[4 ; 7 ; 9 ; 21]$ are consistent with the current findings, which generally showed that the adverse impact caused by $\mathrm{PM}_{2.5}$ is higher than that of $\mathrm{PM}_{\mathrm{C}}$ and $\mathrm{PM}_{10}$, findings which are also supported by previous studies [21;23-25]. For example, Chen et al. [25] reported that $\mathrm{PM}_{2.5}$ was significantly associated with an increased risk of emergency hospital visits. However, contrasting findings from a case-crossover study conducted in Toronto, Canada, showed that $\mathrm{PM}_{\mathrm{C}}$ was more strongly associated with asthma than $\mathrm{PM}_{2.5}$ and $\mathrm{PM}_{10}$ in a time-series analysis [26].

It is still unclear which size of PM has a substantial impact on RESD, irrespective of the currrent study findings, which showed that $\mathrm{PM}_{2.5}$ appeared to be the main driver for the increase in outpatient visits for RESD. Some underlying pathological mechanisms are postulated for the obtained findings. Given that $\mathrm{PM}_{2.5}$ has a smaller size, larger active surface area, and higher capacity for absorbing toxic air pollutants per mass unit [27], this PM can quickly gain access via inhalation into the respiratory tract and deposited in lung 


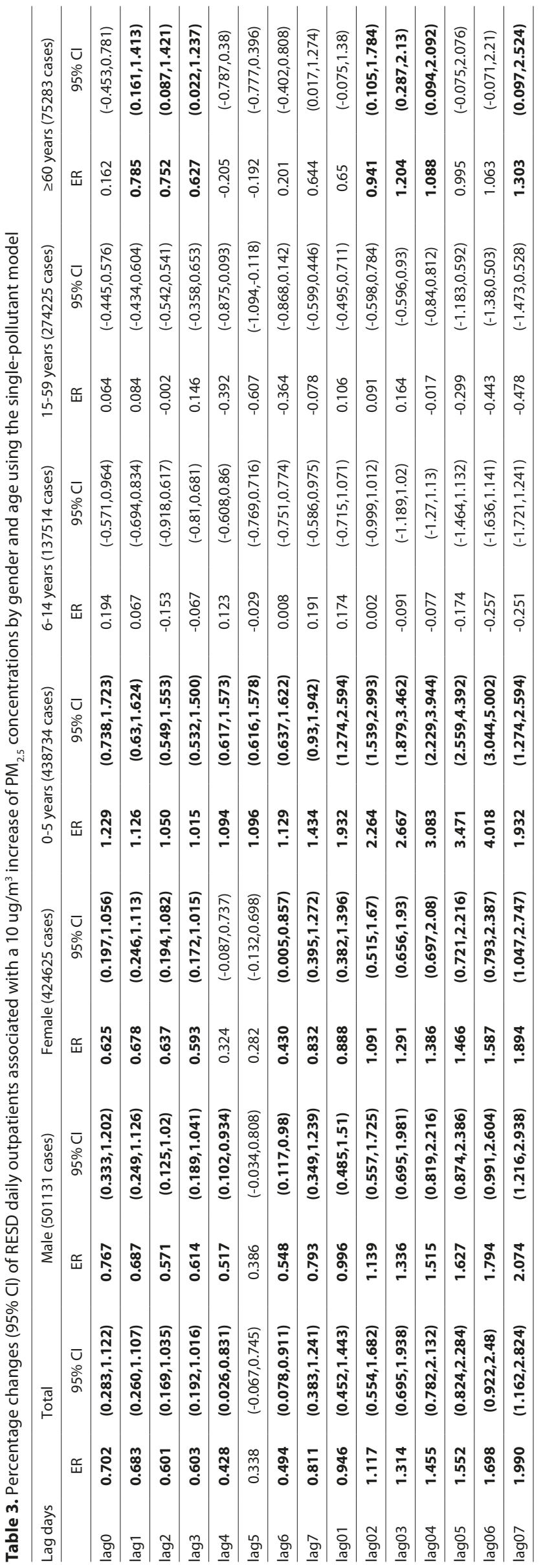




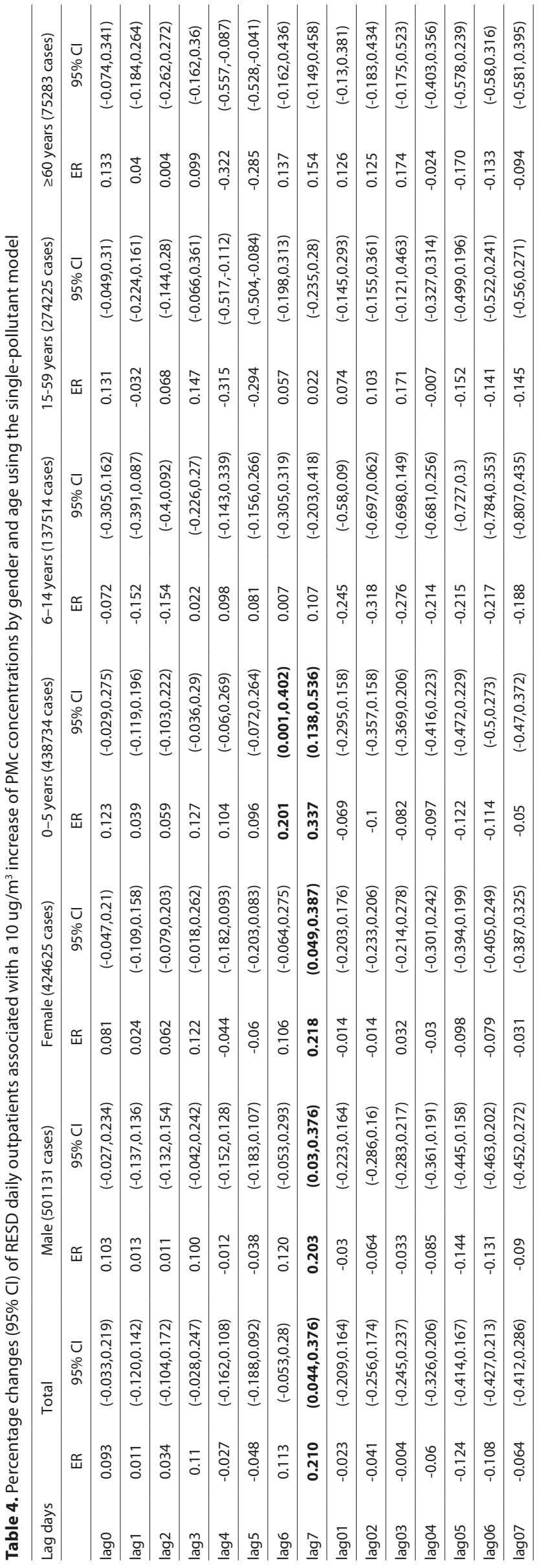




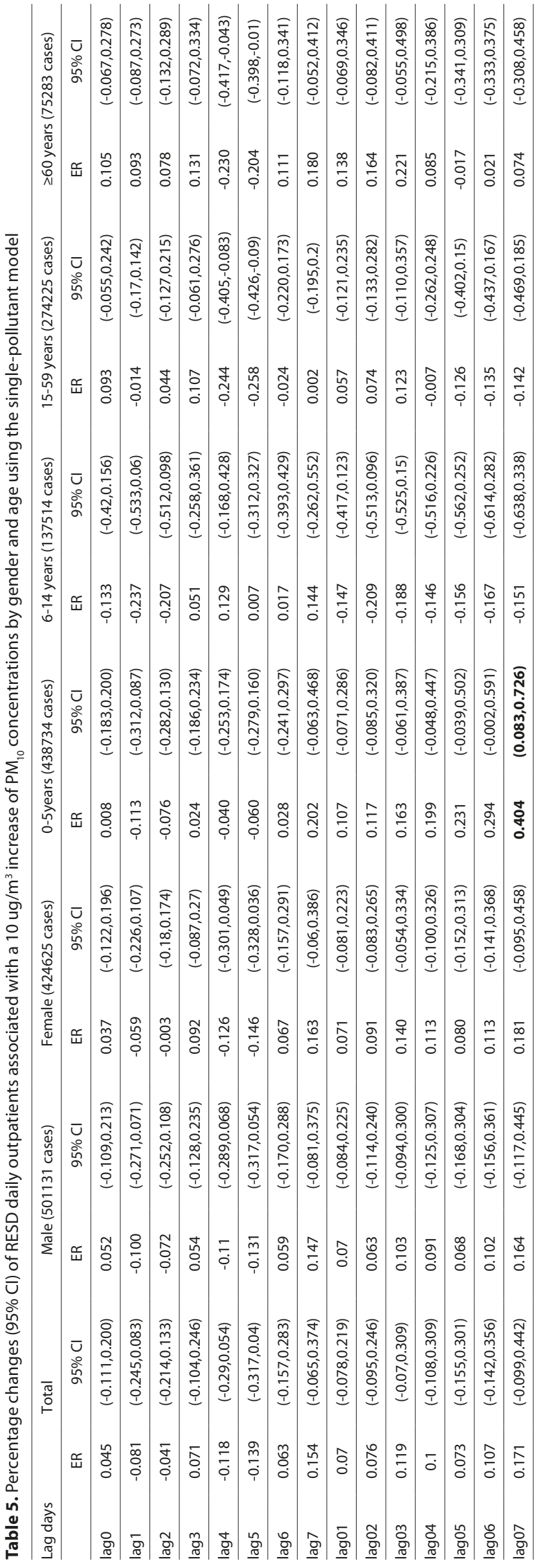




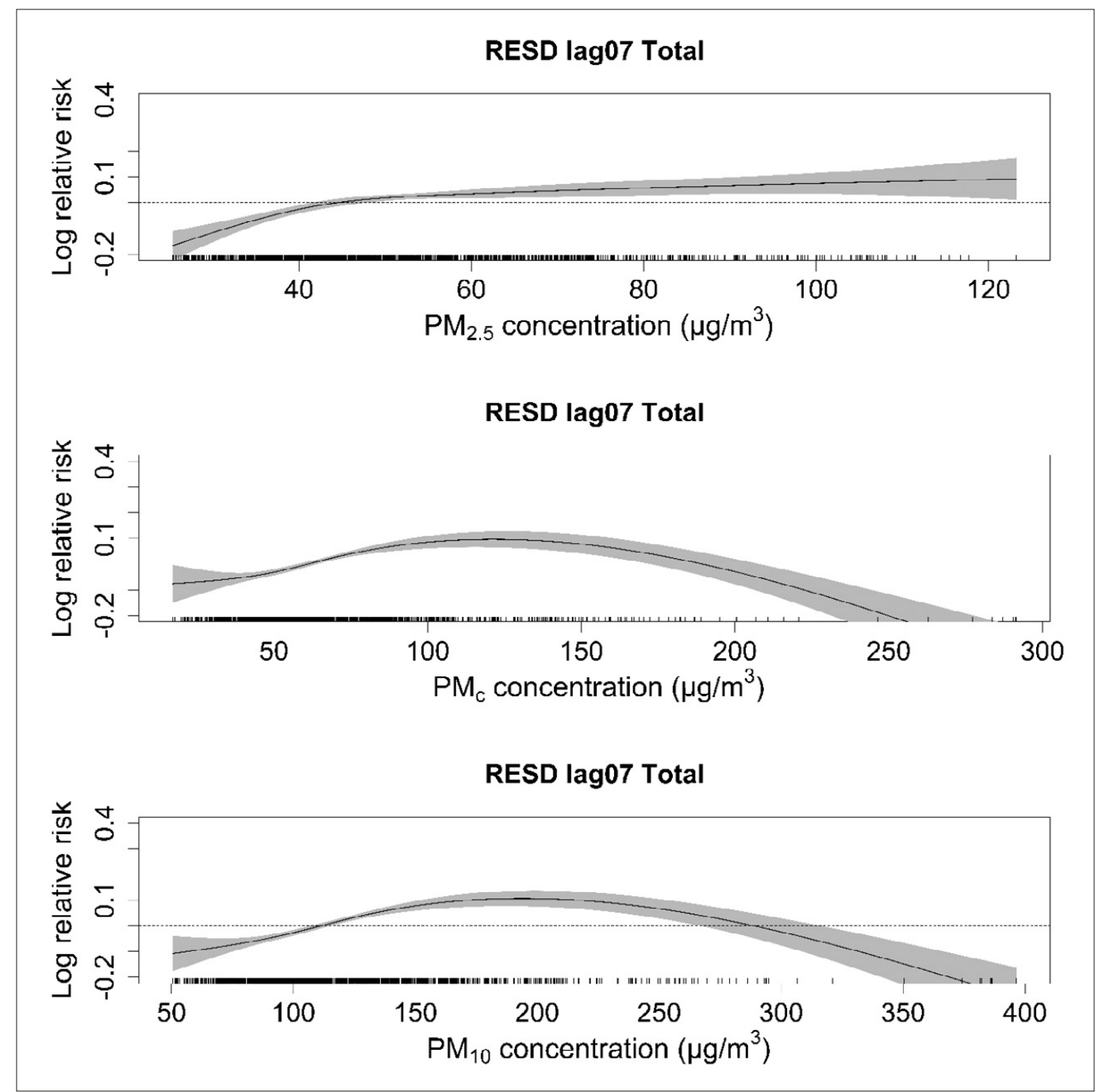

Figure 3. Curve of exposure-reaction relationship between concentration of $\mathrm{PM}_{\mathrm{s}}\left(\mathrm{PM}_{2.5^{\prime}} \mathrm{PM}_{\mathrm{c}} \& \mathrm{PM}_{10}\right)$ and outpatient visits for respiratory disease at lag07

Table 6. Association with a $10 \mathrm{ug} / \mathrm{m}^{3}$ increase in air pollutants for RESD daily outpatients using single, two and three pollutant models during 2014-2017

\begin{tabular}{lcc}
\hline Pollutants and Model $^{\mathrm{a}}$ & $\mathrm{ER}$ & $95 \% \mathrm{Cl}$ \\
\hline $\mathrm{PM}_{2.5}$ & & $(1.162,2.824)$ \\
\hline Single pollutant model & 1.990 & $(0.862,2.579)$ \\
\hline$+\mathrm{NO}_{2}$ & 1.717 & $(0.484,2.532)$ \\
\hline$+\mathrm{SO}_{2}$ & 1.503 & $(0.502,2.549)$ \\
\hline$+\mathrm{NO}_{2}+\mathrm{SO}_{2}$ & 1.520 & \\
\hline $\mathrm{PM}_{\mathrm{c}}$ & & $(-0.412,0.286)$ \\
\hline $\mathrm{Single} \mathrm{pollutant}$ model & -0.064 & $(-0.490,0.208)$ \\
\hline$+\mathrm{NO}_{2}$ & -0.041 & $(-0.511,0.188)$ \\
\hline$+\mathrm{SO}_{2}$ & -0.062 & $(-0.535,0.165)$ \\
\hline$+\mathrm{NO}_{2}+\mathrm{SO}_{2}$ & -0.085 & \\
\hline $\mathrm{PM}_{10}$ & & $(-0.099,0.442)$ \\
\hline $\mathrm{Single} \mathrm{pollutant}$ model & 0.171 & $(-0.188,0.36)$ \\
\hline$+\mathrm{NO}_{2}$ & 0.155 & $(-0.277,0.289)$ \\
\hline$+\mathrm{SO}_{2}$ & 0.145 & $(-0.29,0.275)$ \\
\hline$+\mathrm{NO}_{2}+\mathrm{SO}_{2}$ & 0.160 &
\end{tabular}

Note: The effects of multiday lag (lag07 for $\mathrm{PM}_{2.5^{\prime}} \mathrm{PM}_{c}$ and $\mathrm{PM}_{10}$ ) were used for RESD daily outpatients alveoli [28]. Small fractions are more likely to be deposited in deep pulmonary sections and get into close contact with epithelial cells and macrophages [29], leading to increased airway reactivity, and subsequently promoting oxidative stress and increased inflammation [30]. Larger particles, such as $\mathrm{PM}_{\mathrm{C}}$ and $\mathrm{PM}_{10}$ can be deposited in the upper airways through sedimentation or impaction in the lower airways [28]. This may explain the more significant adverse impact of $\mathrm{PM}_{2.5}$ on human health than $\mathrm{PM}_{\mathrm{C}}$ and $\mathrm{PM}_{10}$.

In the presented study it was found that the ER of $\mathrm{PM}_{2.5}$ was statistically significant throughout the whole lag period and consistently elevated with increased lag days, showing the sustained effects of PM on RESD. The ER peaked at lag 07, lag 05 and lag 07 for $\mathrm{PM}_{2.5}, \mathrm{PM}_{\mathrm{C}}$ and $\mathrm{PM}_{10}$, respectively, though the ER for $\mathrm{PM}_{C}$ and $\mathrm{PM}_{10}$ was not statistically significant. This finding was consistent with that of a study conducted in Denver, USA, by Kim et al. [31]. The authors reported that the impact was more considerable at longer lag periods for total RESD in the five-county Denver metropolitan area. In contrast, some previous studies showed that PM usually showed acute effects on RESD. Yao et al. [21] reported that the peak adverse effect on RESD occurred on lag01 for both $\mathrm{PM}_{2.5}$ and $\mathrm{PM}_{10}$; Qiu et al. [27] found a significant association between asthma hospitalization and $\mathrm{PM}_{\mathrm{C}}$; Jiang et al. [32] 
showed $\mathrm{PM}_{\mathrm{C}}$ generated the maximum impact on respiratory outpatients at lag05.

The heterogeneous findings among these studies may be attributed to the following reasons. First, the compositions of PM pollution vary across different regions [28]. The essential components of $\mathrm{PM}_{25}$ were carbonaceous aerosol, water-soluble ion and a low quantity of polycyclic aromatic hydrocarbons (PAHs) in Lanzhou [33]; PAHs could damage the respiratory system due to their toxicity and carcinogenicity. Second, there were differences in data collection periods, population distribution, medical resource capacity and prevention measures across the studies; hence the impact of PM pollution on health outcomes may be different.

Stratified analysis demonstrated gender differences in the associations of PM pollution with RESD. More substantial effects were observed of $\mathrm{PM}_{2.5}$ and $\mathrm{PM}_{\mathrm{C}}$, but weaker effects of $\mathrm{PM}_{10}$ on RESD in males than females. Though the ERs of $\mathrm{PM}_{\mathrm{C}}$ and $\mathrm{PM}_{10}$ were not statistically significant, the findings were consistent with previous epidemiological studies on air pollution [22;34]. Nevertheless, studies conducted in Beijing and Nanjing reported results that were contrary to the findings obta9ined in the current study. Xu et al. [35] demonstrated that females were at higher risk of RESD after $\mathrm{PM}_{2.5}$ exposure in Beijing; Wang et al. [7] reported that the impact of shortterm PM exposure was not significantly different between males and females in Nanjing. The difference in findings among males and females may be attributed to the following reasons. Lifestyle individual habits of males and females suggest that males tend to have more outdoor activities, which is associated with increased frequency of smoking and alcohol consumption, with subsequent exposure to PM pollution [34]. Circulating sex hormones may also be a factor for the discordant findings among males and females [36].

The presented results suggest that children aged $0-5$ and the elderly aged $\geq 60$ years are more susceptible to the adverse respiratory effects of $\mathrm{PM}$, compared to those aged 6-14 and 15-59 years; furthermore, $\mathrm{PM}_{2.5}$ was the most essential PM triggering RESD in children aged $0-5$ and the elderly aged $\geq 60$ years. These findings were consistent with those reported in previous studies [21;35;37-38]; however, the results reported by Wang et al. [39] showed that younger age groups were more vulnerable to the effects of air pollution than the elderly, which were inconsistent with the findings in the presented study. The differences may be attributed to the physiological structure and immune status in these groups. The immune system is weaker in children aged 0-5 and elderly aged $\geq 60$ years, compared to other age groups; hence, they are more susceptible to the adverse health effects of air pollution.

To the best knowledge of the authors, this is the first study to evaluate the associations of size-fractionated particle matter pollution with outpatient visits for RESD in Lanzhou. The findings provide some reference data for local public health authorities to assist in planning and implementing more efficacious preventative strategies for particulate matter pollution. The analyses were comprehensive, and were controlled for the confounding effects of air pollution variables such as $\mathrm{SO}_{2}$ and $\mathrm{NO}_{2}$.

Some limitations deserve acknowledgment. First, air pollution data collected from air monitoring stations was used to represent the individual exposures; hence, there may be some deviations. Second, it was not possible to control some potential factors, for example, personal habits, living circumstances and chronic diseases like diabetes and hypertension, which could bias the results.

\section{CONCLUSIONS}

The results obtained showed significant associations of increased $\mathrm{PM}_{2.5}$ concentrations with increased daily outpatients visits for RESD with lag effects. There were modest associations for larger particles. In subgroup analysis, the impact of atmospheric PM on outpatient visits for RESD was significantly modified by gender and age; men, and children aged $0-5$ years were more sensitive to $\mathrm{PM}_{2.5}$ pollution. Ther study findings are potentially crucial for formulating preventive strategies to protect the population from the adverse impact of PM pollution. Relevant public health departments should put in place measures to reduce pollution emissions, such as reducing fossil fuel combustion, limiting the number of vehicles on the road, and promoting the use of public transport travel, etc.

\section{Acknowledgements}

This study was supported by National Natural Science Foundation of China (No.71861026) and the China Postdoctoral Science Foundation (No.2016M600827).

\section{REFERENCES}

1. Gao Q, Xu Q, Guo X, Fan H, Zhu H. Particulate matter air pollution associated with hospital admissions for mental disorders: A timeseries study in Beijing, China. Eur Psychiat. 2017; 44: 68-75. http:// doi.org/10.1016/j.eurpsy.2017.02.492

2. Yang Kedi. Environmental Hygiene. Edition 7. Beijing: People's Medical Publishing House; 2012. p. 76-77.

3. Ling SH, Van E, Stephan F. Particulate matter air pollution exposure: role in the development and exacerbation of chronic obstructive pulmonary disease. Int J Chronic Obstr. 2009; 4: 233-43.

4. Zhao YJ, Wang SY, Lang LL, Huang CY, Ma WJ, Lin HL. Ambient fine and coarse particulate matter pollution and respiratory morbidity in Dongguan, China. Environ Pollut. 2017; 222: 126-131. http://doi. org/10.1016/j.envpol.2016.12.070

5. Lu F, Xu DQ, Cheng YB, Dong SX, Guo C, Jiang X, Zheng XY. Systematic review and meta analysis of the adverse health effects of ambient $\mathrm{PM}_{2.5}$ and $\mathrm{PM}_{10}$ pollution in the Chinese population. Environ Res. 2015; 136 : 196-204. http://doi.org/10.1016/j.envres.2014.06.029

6. Lin HL, Tao J, Kan HD, Qian ZM, Chen AL, Du YD, Liu T, Zhang YH, Qi YQ, Ye JJ, Li SM, Li WL, Xiao JP, Zeng WL, Li X, Stamatakis KA, Chen XY, Ma WJ. Ambient particulate matter air pollution associated with acute respiratory distress syndrome in Guangzhou, China. J Expo Sci Env Epid. 2018; 28: 392-399. https://doi.org/10.1038/s41370-0180034-0

7. Wang C, Feng L, Chen K. The impact of ambient particulate matter on hospital outpatient visits for respiratory and circulatory system disease in an urban Chinese population. Sci Total Environ. 2019; 666: 672-679. http://doi.org/10.1016/j.scitotenv.2019.02.256

8. Li R, Jiang QC, Huang XB, Liu F, Gao ZC. Impact of Air Pollutants on Outpatient Visits for Acute Respiratory Outcomes. Int J Env Res Pub He. 2017; 14(1). http://doi.org/10.3390/ijerph14010047

9. Eun JJ, Woo SL, Hyun YJ, Chang HK, Jung SE, Jeong HM, Mi HK, Kwangha L, Ki UK, Hye KP. Effects of particulate matter on respiratory disease and the impact of meteorological factors in Busan, Korea. Resp Med. 2017; 124: 79-87. http://doi.org/10.1016/j.rmed.2017.02.010

10. Xu Q. The effects of particulate matter on emergency room visits in Beijing, based on generalized additive model. Beijing: Capital Medical University; 2017.

11. Ge EJ, Lai KF, Xiao X, Luo M, Fang ZF, Zeng YJ, Ju H, Zhong NS. Differential effects of size-specific particulate matter on emergency department visits for respiratory and cardiovascular diseases in Guangzhou, China. Environ Pollut. 2018; 243(Pt A): 336-345. https:// doi.org/10.1016/j.envpol.2018.08.068 
12. Zhang ZY, Chai PF, Wang JB, Ye ZH, Peng Shen, Lu HC, Jin MJ, Gu MJ, Li D, Lin HB, Chen K. Association of particulate matter air pollution and hospital visits for respiratory diseases: a time-series study from China. Environ Sci Pollut R. 2019; 26(12): 12280-12287. https://doi. org/10.1007/s11356-019-04397-7

13. Zhao JG, Wang SG, Zhang TY, Yu SW, Hu YL, Zhu Z, Shang KZ. The analysis of meteorological factors causing heavy air pollution in Lanzhou. Acta Scientiae Circumstantiae. 2015; 35(5): 1547-1555. http:// doi.org/10.13671/j.hjkxxb.2014.0829

14. Xiao ZH, Shao LY, Zhang N. Chemical Compositions and Sources of PM10 in Winter and Spring in Chengguan District of Lanzhou. Environ Sci Technol. 2011; 34(12): 164-168. http://doi.org/10.3969/j. issn.1003-6504.2011.12.034

15. Wang YN, Jia CH, Tao J, Zhang LM, Liang XX, Ma JM, Gao H, Huang $\mathrm{T}$, Zhang K. Chemical characterization and source apportionment of $\mathrm{PM}_{2.5}$ in a semi-arid and petrochemical-industrialized city, Northwest China. Sci Total Environ. 2016; 573: 1031-1040. https://doi.org/10.1016/j. scitotenv.2016.08.179

16. Tan JH, Zhang LM, Zhou XM, Duan JC, Li Y, Hu JN, He KB. Chemical characteristics and source apportionment of $\mathrm{PM}_{2.5}$ in Lanzhou, China. Sci Total Environ. 2017; 601-602: 1743-175. https://doi.org/10.1016/j. scitotenv.2017.06.050

17. Liao YX, Sun J, Qian ZM, Mei SJ, Li Y, Lu Y, McMillin SE, Lin HL, Lang LL. Modification by seasonal influenza and season on the association between ambient air pollution and child respiratory diseases in Shenzhen, China. Atmos Environ. 2020; 234. https://doi.org/10.1016/j. atmosenv.2020.117621

18. Feng W, Li HB, Wang S, Van Halm-Lutterodt N, An J, Liu Y, Liu MY, Wang XN, Guo XH. Short-term $\mathrm{PM}_{10}$ and emergency department admissions for selective cardiovascular and respiratory diseases in Beijing, China. Sci Total Environ. 2019; 657: 213-221. https://doi. org/10.1016/j.scitotenv.2018.12.066

19. Zhang P, Zhou XY. Health and economic impacts of particulate matter pollution on hospital admissions for mental disorders in Chengdu, Southwestern China. Sci Total Environ. 2020; 733: 139114. https://doi. org/10.1016/j.scitotenv.2020.139114

20. Malig BJ, Green S, Basu R, Broadwin R. Coarse Particles and Respiratory Emergency Department Visits in California. Am J Epidemiol. 2013; 178(1): 58-69. https://doi.org/10.1093/aje/kws451

21. Yao CY, Wang Y, Christopher W, Xu CZ, Christiana K, Lin Y, Zhang $\mathrm{P}$, Yin $\mathrm{P}$, Kin BHL. The association between high particulate matter pollution and daily cause-specific hospital admissions: a time-series study in Yichang, China. Environ Sci Pollut R. 2020; 27: 5240-5250. https://doi.org/10.1007/s11356-019-06734-2

22. Wang AX, Cheng X, Song CB, Ying SM, Li Q, Wu L, Mao HJ. Association between fine particulate matter and asthma hospital outpatient visits in Hangzhou. Environ Sci. 2018; 39(10): 4457-4462 (2018). https://doi. org/10.13227/j.hjkx.201712090

23. Yin GJ, Liu C, Hao LP, Chen YC, Wang WD, Huo JT, Zhao QB, Zhang YH, Duan YS, Fu QY, Chen RJ, Kan HD. Associations between sizefractionated particle number concentrations and COPD mortality in Shanghai, China. Atmos Environ. 2019; 214. https://doi.org/10.1016/j. atmosenv.2019.116875

24. Meng X, Ma YJ, Chen RJ, Zhou ZJ, Chen BH, Kan HD. Size-Fractionated Particle Number Concentrations and Daily Mortality in a Chinese City. Environ Health Persp. 2013; 121(10): 1174-8. https://doi.org/10.1289/ ehp. 1206398

25. Chen GB, Li SS, Zhang YM, Zhang WY, Li DW, Wei XM, He Y, Bell ML, Williams G, Marks GB, Jalaudin B, Abramson MJ, Guo YM. Effects of ambient PM1 air pollution on daily emergency hospital visits in China: an epidemiological study. The Lancet Planetary Health. 2017; 1(6): e221-e229. https://doi.org/10.1016/S2542-5196(17)30100-6

26. Lin M, Chen Y, Burnett RT, Villeneuve PJ, Krewski D. The Influence of Ambient Coarse Particulate Matter on Asthma Hospitalization in Children: Case-Crossover and Time-Series Analyses. Environ Health Persp. 2002; 110(6): 575-581. https://doi.org/10.1289/ehp.02110575.

27. Qiu H, Yu ITS, Tian LW, Wang XR, Tse LA, Tam W, Wong TW. Effects of Coarse Particulate Matter on Emergency Hospital Admissions for Respiratory Diseases: A Time-Series Analysis in Hong Kong. Environ Health Persp. 2012; 120(4): 572-6. https://doi.org/10.1289/ehp.1104002

28. Li T, Hu R, Chen, Z, Li QY, Huang SX, Zhou LF. Fine particulate matter $\left(\mathrm{PM}_{25}\right)$ : The culprit for chronic lung diseases in China. Chronic diseases and translational medicine. 2018; 4(3): 176-186. https://doi. org/10.1016/j.cdtm.2018.07.002

29. Han YQ, Zhu T. Health effects of fine particles $\left(\mathrm{PM}_{2.5}\right)$ in ambient air. Science China (Life Sciences). 2015; 58(06): 624-626. https://doi. org/10.1007/s11427-015-4878-4

30. Zhang YQ, Ding Z, Xiang QQ, Wang W, Huang L, Mao FY. Short-term effects of ambient PM1 and PM2.5 air pollution on hospital admission for respiratory diseases: Case-crossover evidence from Shenzhen, China. Int J Hyg Envir Heal. 2020; 224. https://doi.org/10.1016/j. ijheh.2019.11.001

31. Kim SY, Peel JL, Hannigan MP, Dutton SJ, Sheppard L, Clark ML, Vedal S. The temporal lag structure of short-term associations of fine particulate matter chemical constituents and cardiovascular and respiratory hospitalizations. Environ Health Pers. 2020; 120(8): 1094-1099. https://doi.org/10.1289/ehp.1104721

32. Jiang JJ, Niu Y, Liu C, Chen RJ, Cao JY, Kan HD, Cheng YX. Shortterm exposure to coarse particulate matter and outpatient visits for cardiopulmonary disease in a Chinese city. 199110686. Ecotox Environ Safe. 2020; 199: 110686. https://doi.org/10.1016/j.ecoenv.2020.110686

33. Li YH. Chemical characteristics and source apportionment of atmospheric fine particles in Lanzhou city. Lanzhou: Lanzhou University; 2015.

34. Zuo BQ, Liu C, Chen RJ, Kan HD, Sun J, Zhao J, Wang C, Sun Q, Bai HJ. Associations between short-term exposure to fine particulate matter and acute exacerbation of asthma in Yancheng, China. Chemosphere. 2019; 237. https://doi.org/10.1016/j.chemosphere.2019.124497

35. Xu Q, Li X, Wang S, Wang C, Huang FF, Gao Q, Wu LJ, Tao LX, Guo J, Wang W, Guo XH. Fine particulate air pollution and hospital emergency room visits for respiratory disease in urban areas in Beijing, China, in 2013. Plos One.2016; 11(4). http://doi.org/10.1371/journal.pone.0153099

36. Faustini A, Stafoggia M, Berti G, Bisanti L, Chiusolo M, Cernigliaro A, Mallone S, Primerano R, Scarnato C, Simonato L, Vigotti MA, Forastiere $\mathrm{F}$. The relationship between ambient particulate matter and respiratory mortality: a multi-city study in Italy. Eur Respir J. 2011; 38(3): 538-547. http://doi.org/10.1183/09031936.00093710

37. Cordova JED, Aguirre VT, Apestegui VV, Ibarguen LO, Vu BN, Steenland K, Rengifo GGF. Association of PM2.5 concentration with health center outpatient visits for respiratory diseases of children under 5 years old in Lima, Peru. Environ Health. 2020; 19(S2): 1-32. https:// doi.org/10.1186/s12940-020-0564-5

38. Nascimento AP, Santos JM, Mill JG, de Souza JB, Reis NC, Reisen VA. Association between the concentration of fine particles in the atmosphere and acute respiratory diseases in children. Rev Saude Publ. 2017; 51. https://doi.org/10.1590/S1518-8787.2017051006523

39. Wang MZ, Zheng S, Wang SG, Tao Y, Shang KZ. The weather temperature and air pollution interaction and its effect on hospital admissions due to respiratory system diseases in western China. Biomed Environ Sci. 2013; 26(5): 403-407. https://doi.org/10.3967/0895-3988.2013.05.011 